EON • Volume 14, Issue 4 - September 2021

\title{
ISMTE Plans Fall Global
}

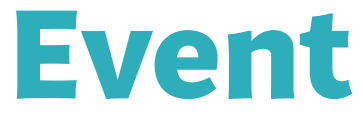

\author{
Julie Nash ${ }^{1}$
}

${ }^{1}$ Senior Partner, J\&J Editorial

Published on: Sep 15, 2021

License: Creative Commons Attribution-NonCommercial-NoDerivatives 4.0 International License (CC-BY-NC-ND 4.0). 


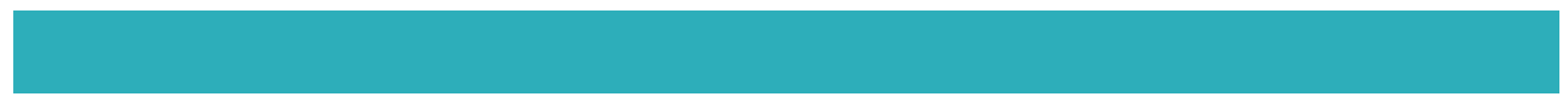

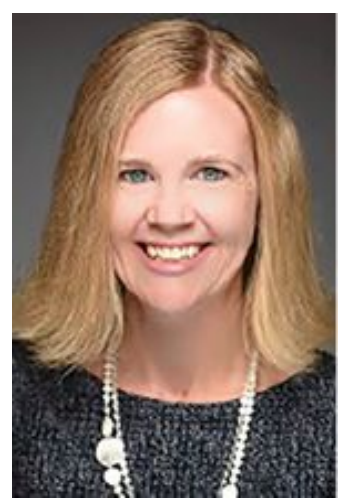

Julie Nash, ISMTE Immediate Past President
With summer almost here, you might be wondering what ISMTE has in store for its annual meeting. This year, it will be a worldwide event.

ISMTE will host sessions in all three of its meeting regions-North America, Europe, and Asia Pacific-in a joint conference held October 11-14. The ISMTE Global Event is the first of its kind for the society and for the industry. With the meeting being virtual again this year, the ISMTE leadership decided it was a good time to bring together members from around the world to provide best practices and developments on common issues we face in scholarly publishing.

The overall theme for the Global Event is "Unified Progress: Moving Forward Together in Scholarly Communications," focusing on similar issues, questions, and problems facing publishing professionals throughout the world. The event will kick off with all attendees invited to the same Opening Ceremony, which will feature society updates, networking, entertainment, and giveaways. Each of the following days will have its own theme: Journal Management, Diversity, Equity \& Inclusion, and Open Access. Sessions on these themes will be conveniently hosted in the various regional time zones.

Each region has its own subcommittee working on the session topics, recruiting regional speakers, and creating networking opportunities. The goal is to have similar content from the three regions but with the specific perspectives of North America, Europe, and Asia Pacific.

All sessions will be recorded so attendees will have the opportunity to watch sessions from other regions when it is convenient-this will be an excellent opportunity to broaden your horizons beyond your home region, making you more adept than ever to address the global nature of scholarly publishing.

The ISMTE Global Event is a unique opportunity to network with peers from across the globe and to hear talks from international experts. Save the dates on your calendar and watch for programming updates on the Events section of the ISMTE website. 


\section{ISMTE Resources}

Are you looking for guidance or tips and tricks to improve your editorial office? ISMTE has a rich library of resources that includes guidance on getting started in the editorial office, improving your editorial office, supporting authors and reviewers, promoting your journal, editorial reporting, and more! To peruse ISMTE's resource library, please visit www.ismte.org/page/Resources. 